EUROPEAN ORGANIZATION FOR NUCLEAR RESEARCH

European Laboratory for Particle Physics

\title{
HE II TWO PHASE FLOW IN AN INCLINABLE 22 m LONG LINE
}

\author{
B. Rousset ${ }^{1}$, A. Gauthier ${ }^{1}$, B. Jager ${ }^{1}$, and R. van Weelderen ${ }^{2}$
}

\begin{abstract}
In the line of previous work done at CEA Grenoble, large size experiments were performed with the support of CERN for the validation of the LHC two phase superfluid helium cooling scheme. In order to be as close as possible to the real configuration, a straight, inclinable $22 \mathrm{~m}$ long line of $40 \mathrm{~mm}$ I.D. was built. Very accurate measurements of temperatures and pressures obtained after in situ re-calibration and verified by independent sensors allowed us to validate our two-phase flow model. Although we focus on pressure losses and heat exchange results in relation to power injected, additional measurements such as quality, void fraction, and total mass flow rate enable a complete description of the two-phase flow. Experiments were carried out to cover the whole range of the future LHC He II two-phase flow heat exchanger pipe: slope between 0 and $2.8 \%$, temperature between 1.8 and $2 \mathrm{~K}$, total mass flow rate up to $7.5 \mathrm{~g} / \mathrm{s}$. Results confirm the validity of choice for the LHC cooling scheme.
\end{abstract}

1 CEA Grenoble / Département de Recherche Fondamentale sur la Matière Condensée/SBT, 17 rue des Martyrs, 38054 Grenoble Cedex 9, France.

2 LHC Division, CERN, 1211 Geneva 23, Switzerland

Presented at the 1999 Cryogenic Engineering and International Cryogenic Materials Conference

(CEC-ICMC'99), 12-16 July 1999, Montreal, Canada

\author{
Administrative Secretariat \\ LHC Division \\ CERN \\ CH - 1211 Geneva 23 \\ Switzerland \\ Geneva, 1 December 1999
}




\title{
HE II TWO PHASE FLOW IN AN INCLINABLE 22 m LONG LINE
}

B. Rousset ${ }^{1}$, A. Gauthier ${ }^{1}$, B. Jager ${ }^{1}$, R. van Weelderen ${ }^{2}$

${ }^{1}$ C.E.A. Grenoble / Département de Recherche Fondamentale sur la Matière Condensée/SBT, 17 rue des Martyrs, 38054 Grenoble Cédex 9, France.

${ }^{2}$ LHC Division, CERN

1211 Geneva 23, Switzerland

\begin{abstract}
In the line of previous work done at CEA Grenoble, large size experiments were performed with the support of CERN for the validation of the LHC two phase superfluid helium cooling scheme. In order to be as close as possible to the real configuration, a straight, inclinable $22 \mathrm{~m}$ long line of $40 \mathrm{~mm}$ I.D. was built. Very accurate measurements of temperatures and pressures obtained after in situ re-calibration and verified by independent sensors allowed us to validate our two-phase flow model. Although we focus on pressure losses and heat exchange results in relation to power injected, additional measurements such as quality, void fraction, and total mass flow rate enable a complete description of the two-phase flow. Experiments were carried out to cover the whole range of the future LHC He II two-phase flow heat exchanger pipe: slope between 0 and $2.8 \%$, temperature between 1.8 and $2 \mathrm{~K}$, total mass flow rate up to $7.5 \mathrm{~g} / \mathrm{s}$. Results confirm the validity of choice for the LHC cooling scheme.
\end{abstract}

\section{INTRODUCTION}

LHC $^{1}$ will use He II two-phase flow as the cold source. In order to maintain the magnet temperature as low as possible, two constraints have to be taken into consideration: the two-phase flow pressure losses (which means temperature difference between inlet and outlet of He II saturated flow, i.e. longitudinal $\Delta \mathrm{T}$ ) and the heat exchange between the saturated flow and the static He II pressurized bath in which the magnets are immersed 
(which means temperature difference between saturated flow and pressurized helium in a magnet cross section, i.e. transversal $\Delta \mathrm{T}$ ).

In the framework of LHC cooling scheme studies, previous experiments were performed $^{2,3,4}$ using a $40 \mathrm{~mm}$ I.D., $1.4 \%$ slope helical pipe and a He II two-phase flow model was constructed. Obtained results gave us confidence in this co-current two-phase flow model and justified further experiments to fully validate the LHC cooling scheme. In particular, the influence of the slope (ranging from 0 to $1.4 \%$ in case of LHC) had to be checked. Furthermore, the excess thermal heat exchange behaviour observed at high Vgs (Vgs represents the superficial vapour velocity, i.e. the vapour velocity if the vapour would occupied the whole cross section) had to be confirmed for a long straight line to avoid entrance and exit effects. In this paper, results on an inclinable straight pipe are presented.

\section{DESCRIPTION OF TEST LOOP AND EXPERIMENT}

The "Cryoloop" (Fig. 1) mainly consists of an inlet box used to create the inlet quality, the $22 \mathrm{~m}$ inclinable straight line, and an outlet saturated bath where excess liquid is evaporated.

The main measurements consist of the total mass flow rate (taken at room temperature), the saturated temperature and differential pressure between the extremities of the line (both used to calculate pressure losses), all powers injected (in order to calculate the quality), temperature increase in the pressurized chamber when power is on (which gives access to the thermal heat exchange) and visualization of the flow.

\section{RESULTS}

\section{Hydraulic Results}

First, the tube friction factor was determined in Reynolds similitude using nitrogen flow at room temperature. Best fit is smooth tube correlation (Fig. 2), which was adopted for wall friction factor in our two-phase flow model. The interfacial friction factor introduced in the model follows the Hanratty correlation as previously reported ${ }^{3,4}$.

In situ calibration of the thermometers located along the two-phase flow enabled temperature measurements with $10^{-3} \mathrm{~K}$ accuracy.

On each figure, mass flow rate represents the sum of liquid and vapour mass flow rates.

Figure 3 compares pressure loss measurements derived from various sensors. Square symbols represent pressure losses between inlet and outlet boxes, respectively, measured with a differential pressure transducer and by means of immersed thermometers (see Fig. 1). The very good agreement confirms thermodynamic equilibrium in each box and good sensor accuracy. Line and circle illustrate comparison of measured and predicted pressure losses over the $22 \mathrm{~m}$ long line only (thereby excluding entrance and exit effects). The agreement is excellent and justifies the code assumptions ${ }^{3}$. Difference between square symbols (showing results given by sensors connected to the inlet box where liquid and vapour are at the rest) and open circle (showing results given by sensors connected to the line) are mainly due to entrance effects, i.e. acceleration of the two-phase flow at the inlet of the line. 


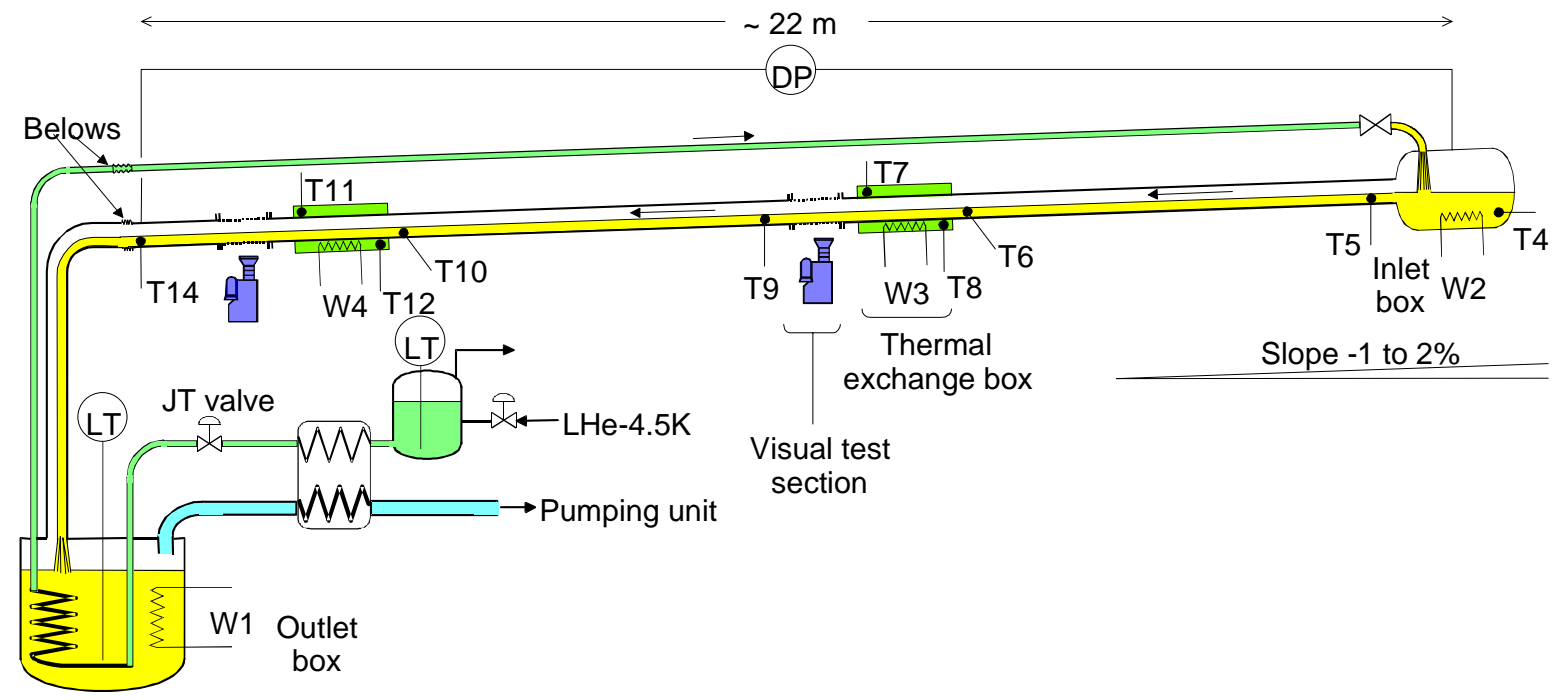

Figure 1. Test facility scheme

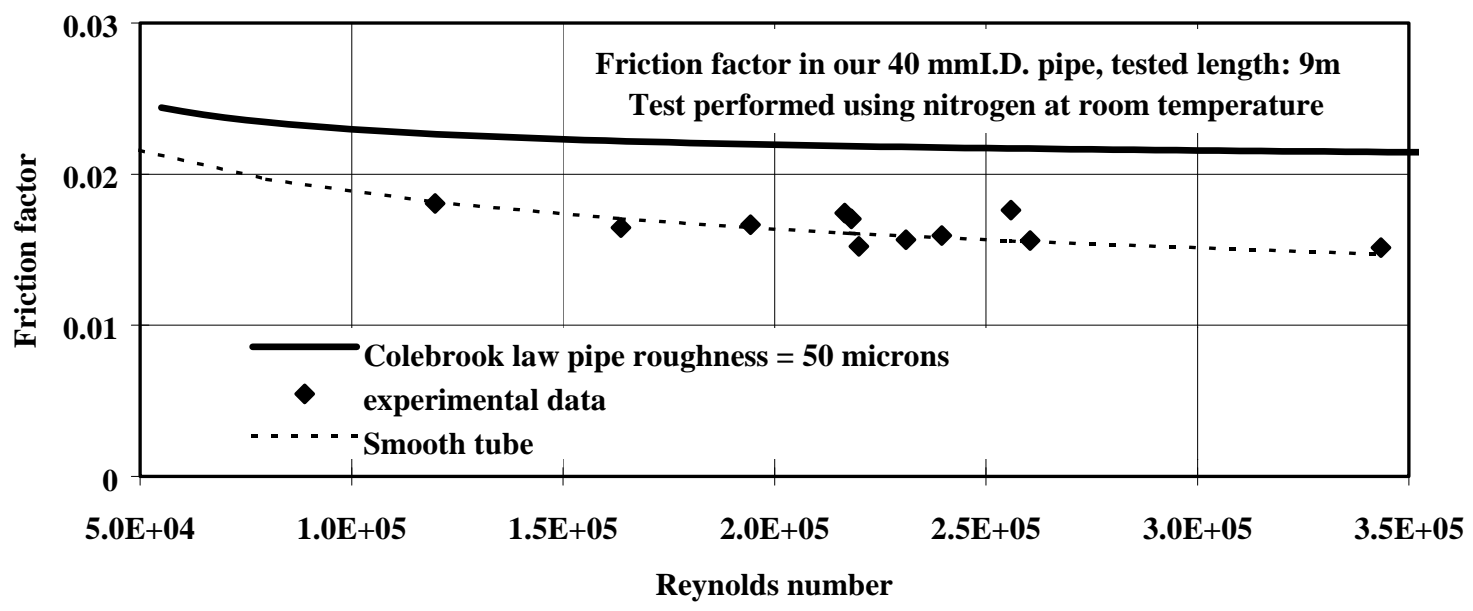

Figure 2. Friction factor calibration

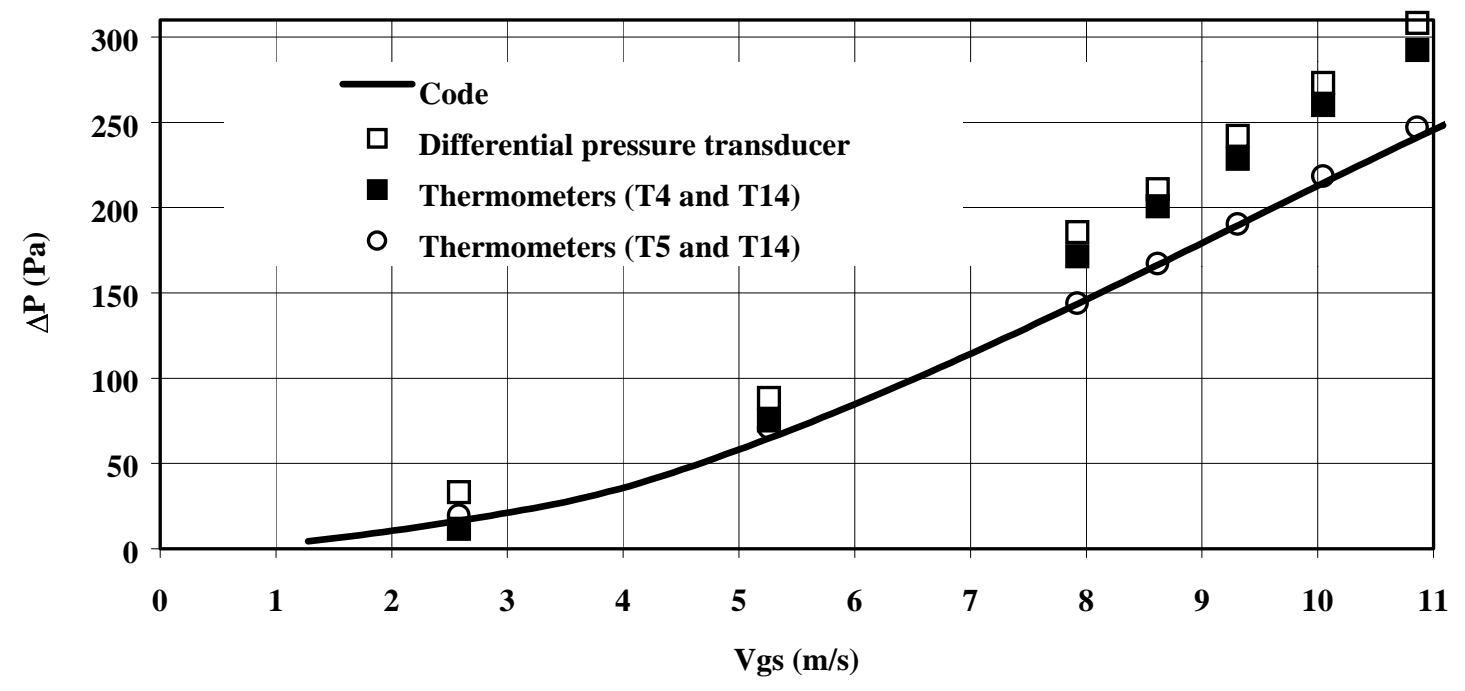

Figure 3. Various pressure losse estimations (slope $0 \%$, total mass flow $7.2 \mathrm{~g} / \mathrm{s}$, temperature $1.77 \mathrm{~K}$ ) 


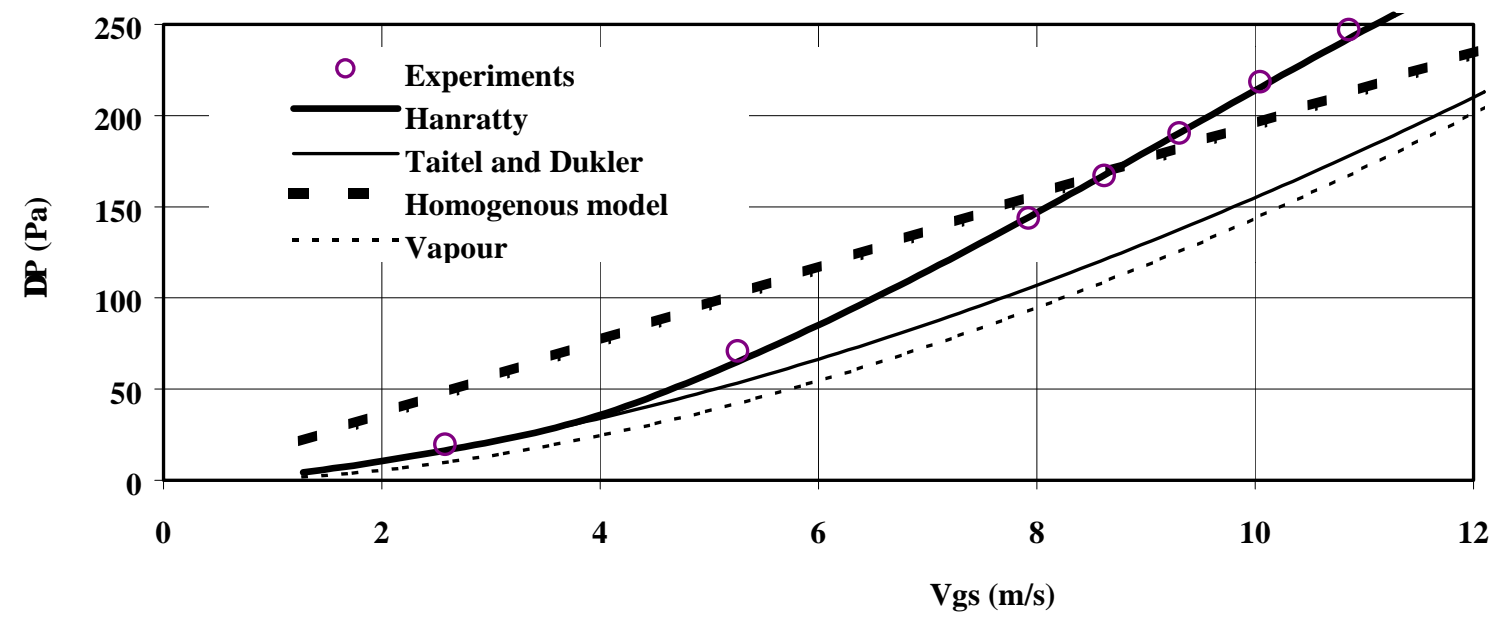

Figure 4. Experiment and model comparisons (slope 0\%, total mass flow $7.2 \mathrm{~g} / \mathrm{s}$, temperature $1.77 \mathrm{~K}$ )

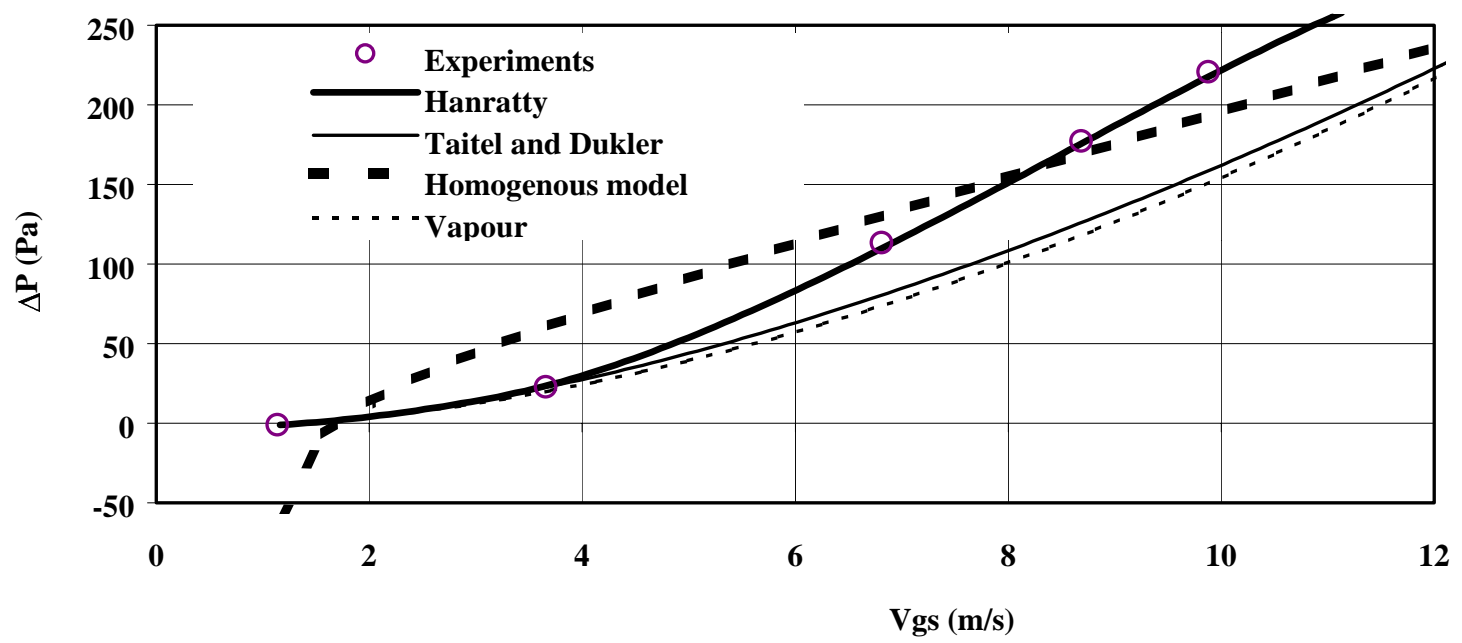

Figure 5. Experiment and model comparisons (slope $2.8 \%$, total mass flow $7.3 \mathrm{~g} / \mathrm{s}$, temperature $1.77 \mathrm{~K})$

Figures 4 and 5 compare the experiments with various models. As flow is stratified, the homogenous model gives worst results. Pressure losses are mainly due to the friction of vapour flow which explains the good agreement of vapour, Taitler and Dukler ${ }^{5}$ and Hanratty ${ }^{6}$ models at low Vgs, especially for large slopes where liquid occupies a small fraction of the cross section. Increasing Vgs results in a wavy interface with droplets dragging and Hanratty correlation has to be employed to represent flow behaviour.

On Figure 6, the curve obtained for $1.77 \mathrm{~K}$ is below the $1.91 \mathrm{~K}$ one. This result is different if injected power replaces Vgs in the abscissa axe. Due to vapour density changes with temperature, the same power injected results in different Vgs, e.g. 120 watt injected correspond to a Vgs of $11 \mathrm{~m} / \mathrm{s}$ at $1.77 \mathrm{~K}$ and a $\mathrm{Vgs}$ of $7.6 \mathrm{~m} / \mathrm{s}$ at $1.91 \mathrm{~K}$, and it is clear on Fig. 6 that resulting pressure loss is higher at low temperature.

Finally, the influence of liquid mass flow rate can be deduced from Figure 7. This parameter has negligible effect, which confirms that pressure losses are mainly due to vapour flow. 


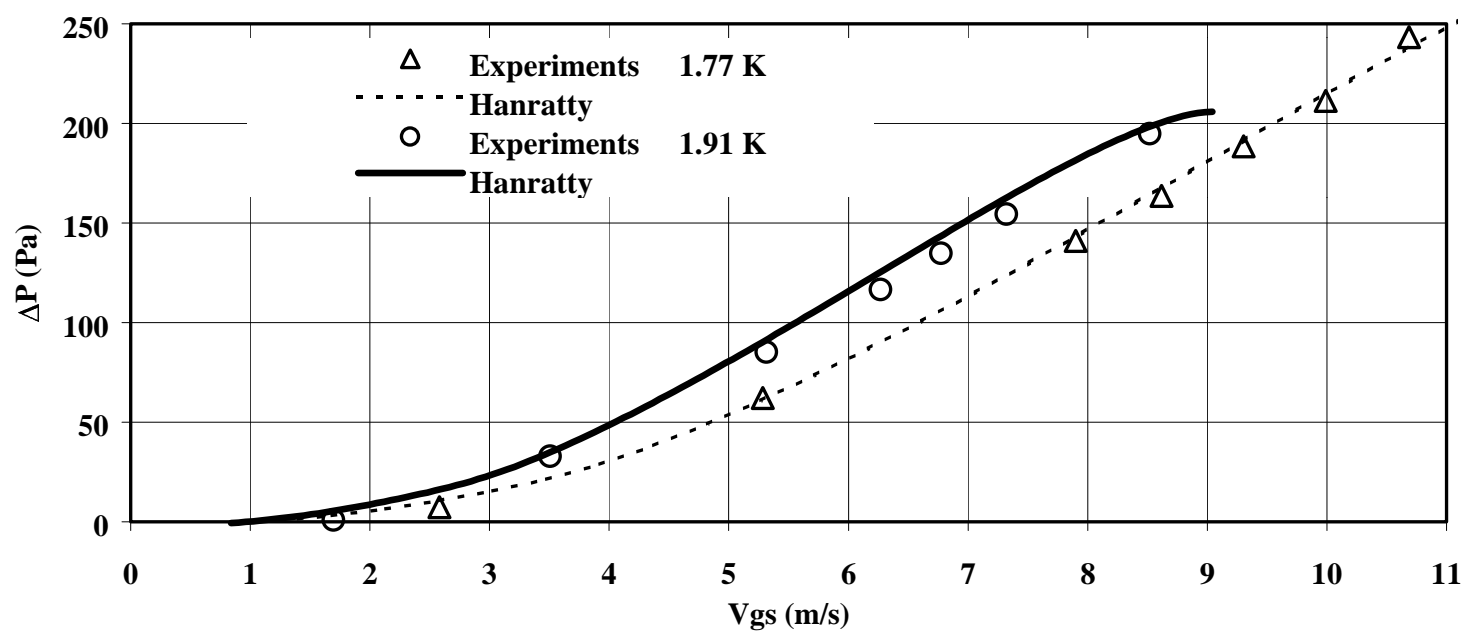

Figure 6. Temperature influence (slope $1.4 \%$, total mass flow $7.2 \mathrm{~g} / \mathrm{s}$ )

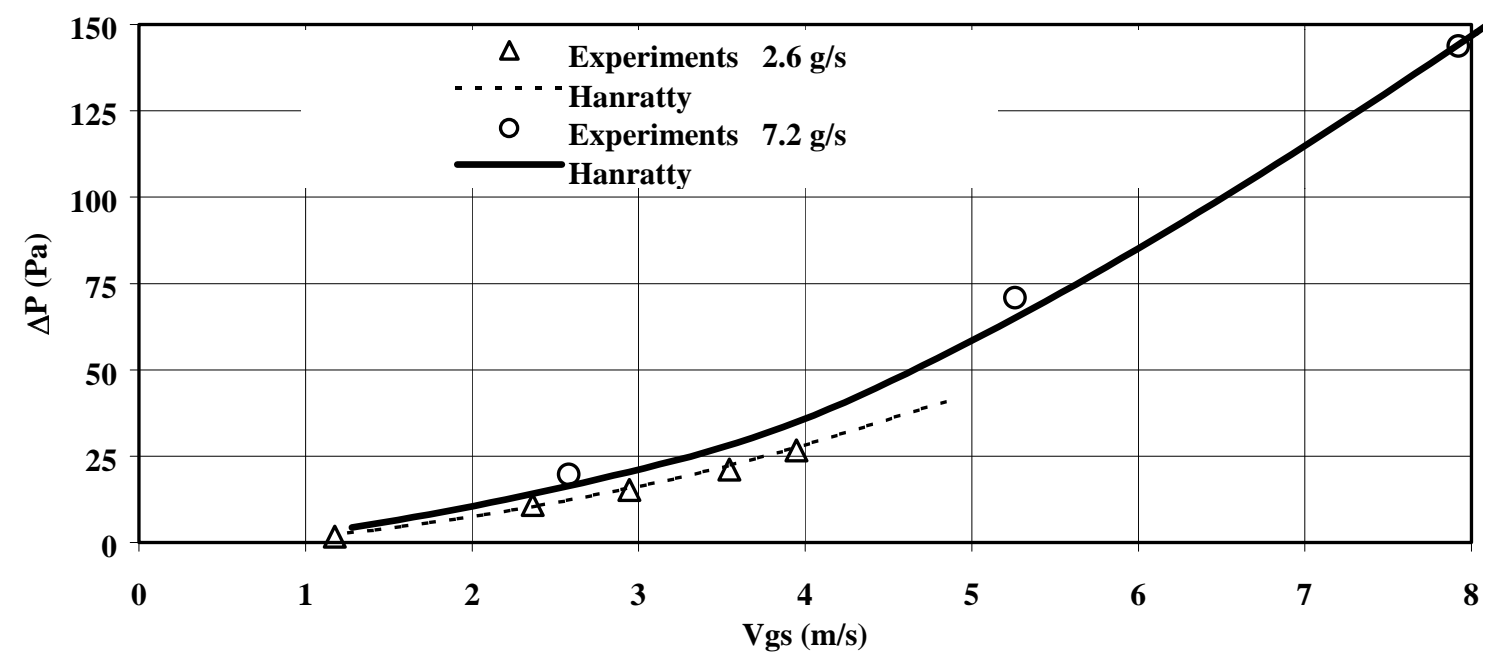

Figure 7. Total mass flow influence (slope $0 \%$, temperature $1.77 \mathrm{~K}$ )

\section{Thermal Results}

One other goal for this new test circuit was the confirmation of excess heat exchange with respect to stratified flow observed on the helicoidal line (i.e. heat exchange increases at high Vgs while liquid mass flow decreases) and the potential influence of using a straight line. As shown on figure 1, two heat exchange boxes instrument the Cryoloop. One is located $10 \mathrm{~m}$ downstream of the inlet, and the other $20 \mathrm{~m}$ downstream of the inlet. Results obtained are identical for the two boxes, and only data acquired on the second box are presented here.

Figure 8 compares the helicoidal line with the present Cryoloop. In both cases, heat flux to be transferred from pressurized bath to saturated flow is equal to $22 \mathrm{~W} / \mathrm{m}^{2}$ (value calculated using the whole pipe perimeter). Excess wetting is always present but appears at higher Vgs in the Cryoloop. This excess wetting consists probably of a tiny liquid layer due to interception of droplets by the pipe wall.

To verify this assumption, heat flux to be transferred was increased in order to dry out the wall liquid layer. The result is that this excess wetting can be partially evaporated when heat flux is increased (figure 9). Furthermore, the wetting dependence with heat flux exhibited a critical vapour velocity which is consistent with the apparition of excess wetting. 
Low Vgs. On Figures 10, 11 and 12, numerical and experimental curves are parallel at low Vgs. The under-estimation of the wetting prediction could be due to wavy flow. Gravity plays a major role and wetting varies considerably with slope. As Vgs decreases, two-phase flow tends to an open channel liquid flow. Experimental slope uncertainties can also explain difference between measured and calculated values, especially for the horizontal case.

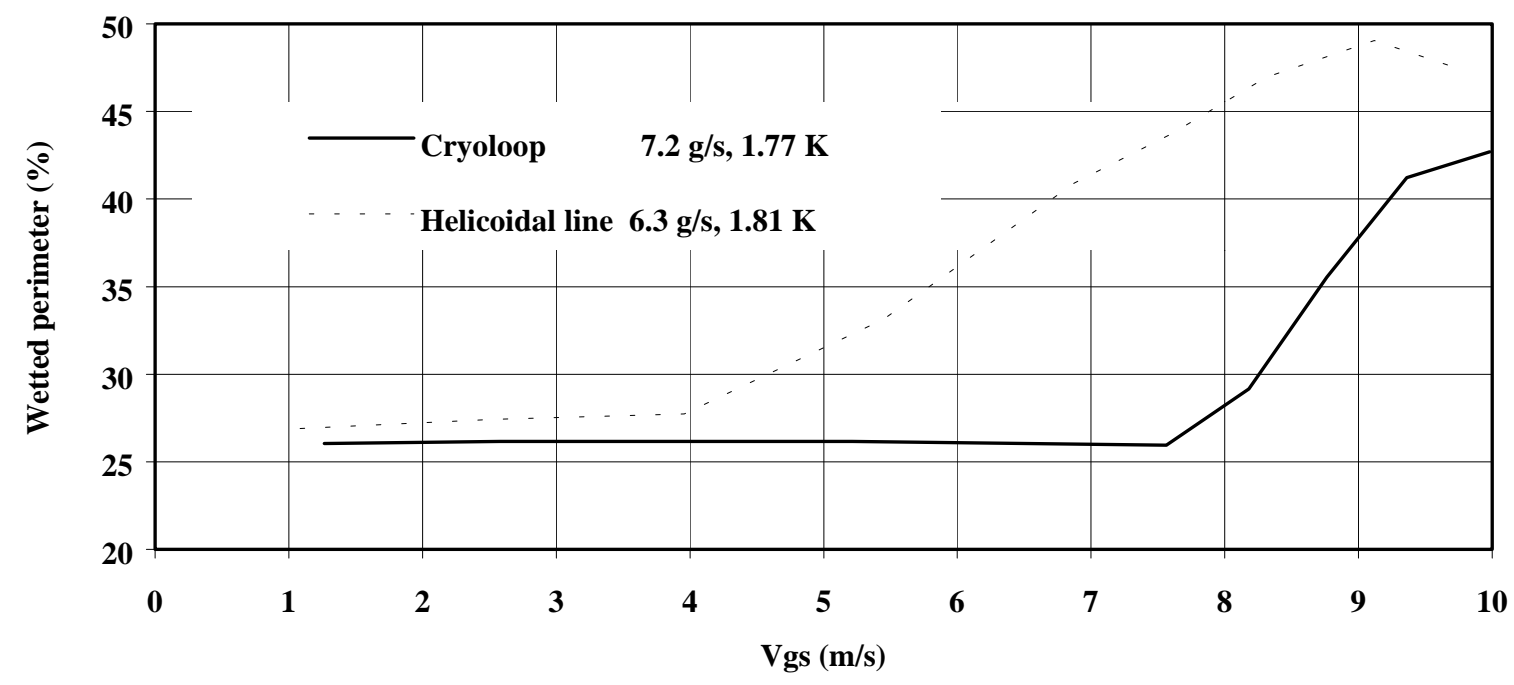

Figure 8. Comparison of thermal heat exchange for helicoidal line and cryoloop (slope 1.4\%, heat flux $22 \mathrm{~W} / \mathrm{m}^{2}$ )

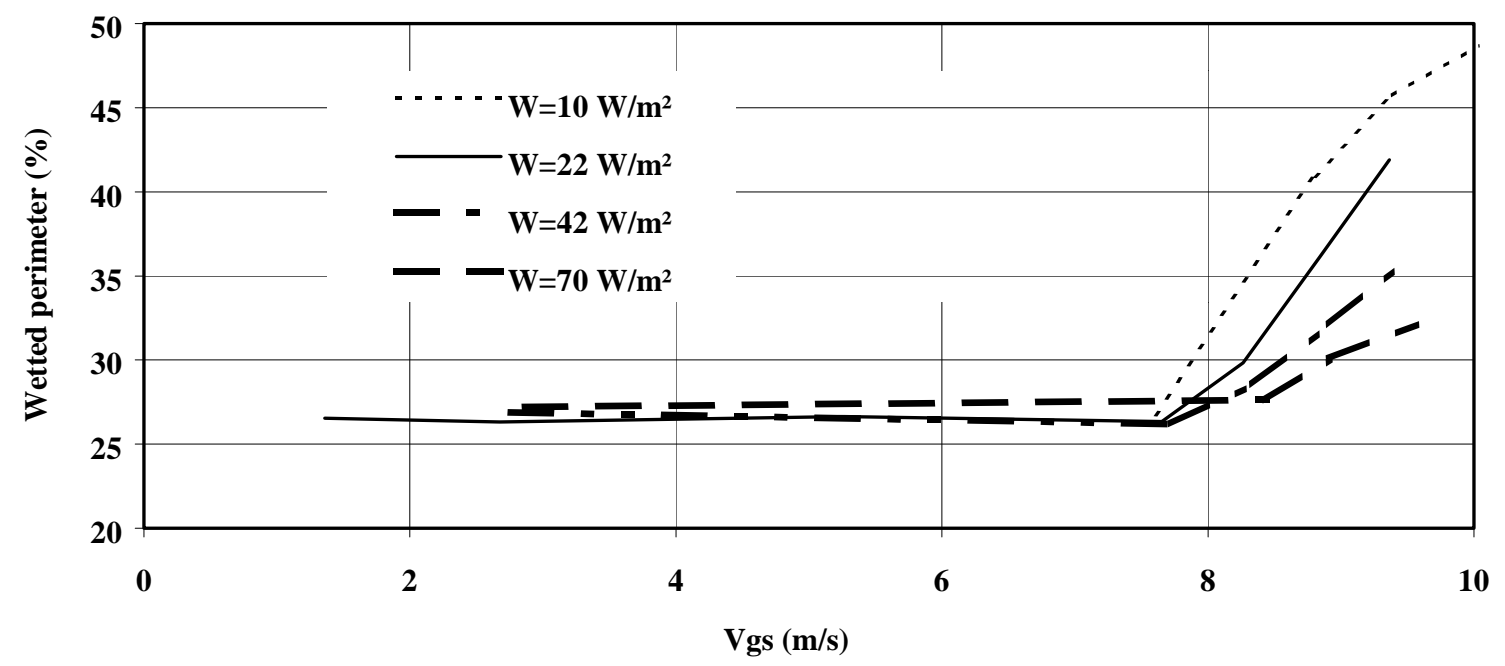

Figure 9. Influence of heat flux on apparent wetted perimeter (slope 1.4\%, total mass flow $7.2 \mathrm{~g} / \mathrm{s}$, temperature $1.77 \mathrm{~K}$ )

High Vgs. Gravity has no influence, even on over-wetting. Unfortunately, it was not possible to access the mass flow or temperature influence, because in our experiments critical Vgs was not obtained for all curves. Over wetting is probably due to liquid droplet deposition on wall. The model, which use separate vapour and liquid flow can't take into account such phenomena. 


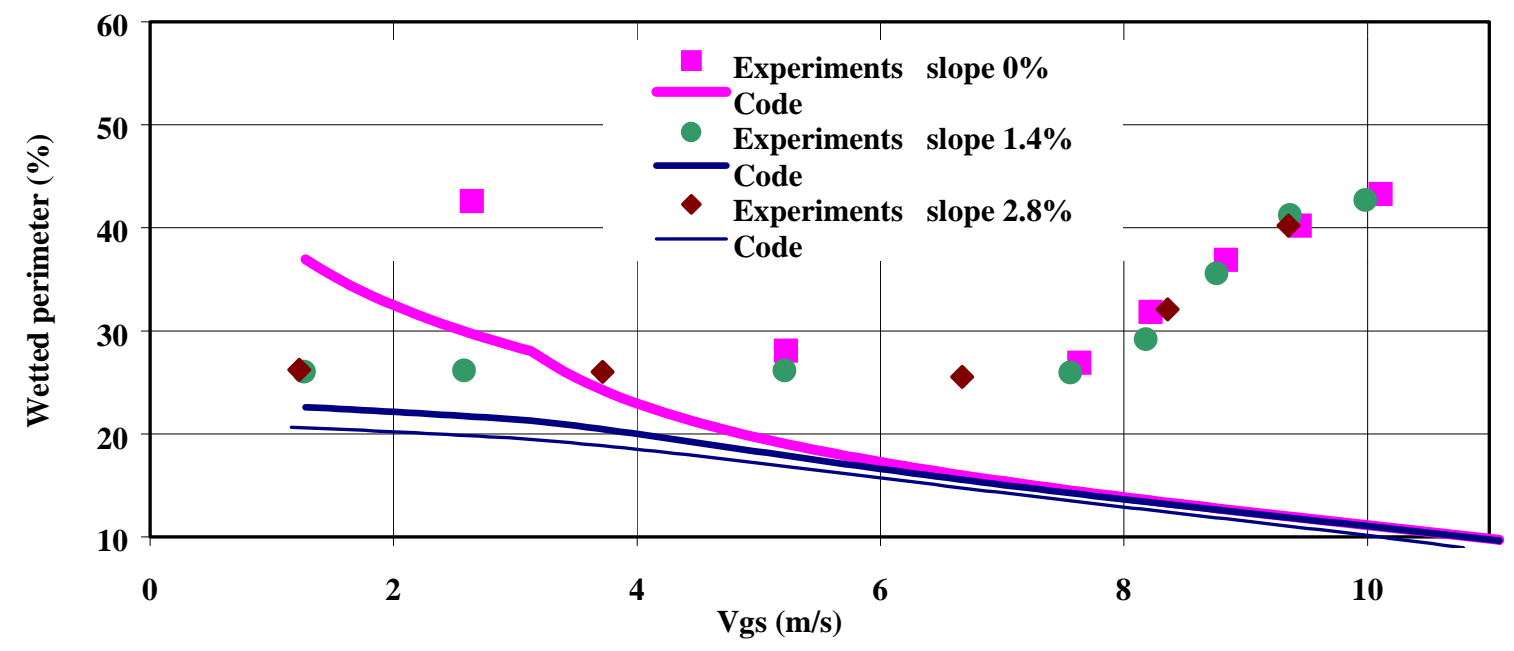

Figure 10. Slope influence (total mass flow $7.2 \mathrm{~g} / \mathrm{s}$, temperature between 1.77 and $1.8 \mathrm{~K}$, heat flux $22 \mathrm{~W} / \mathrm{m}^{2}$ )

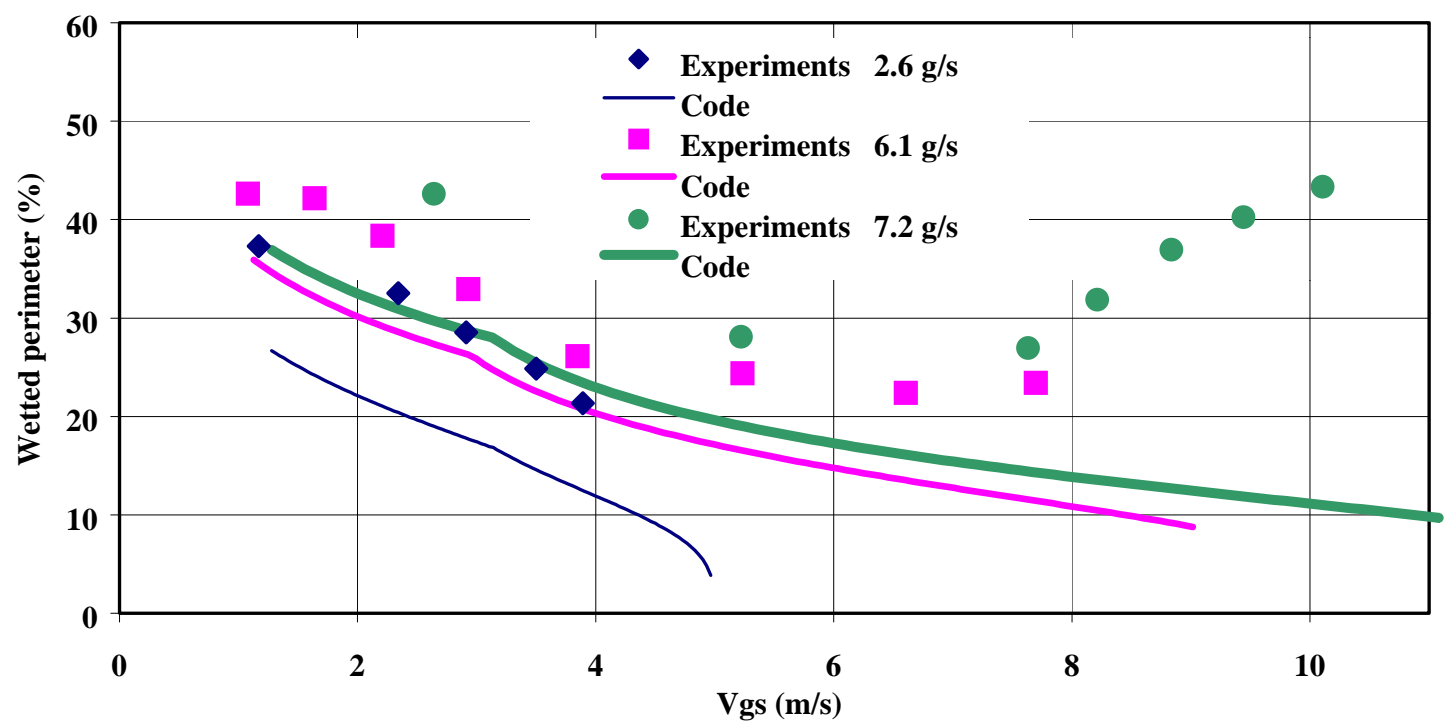

Figure 11. Total mass flow influence (slope 0\%, temperature between 1.77 and $1.8 \mathrm{~K}$, heat flux $22 \mathrm{~W} / \mathrm{m}^{2}$ )

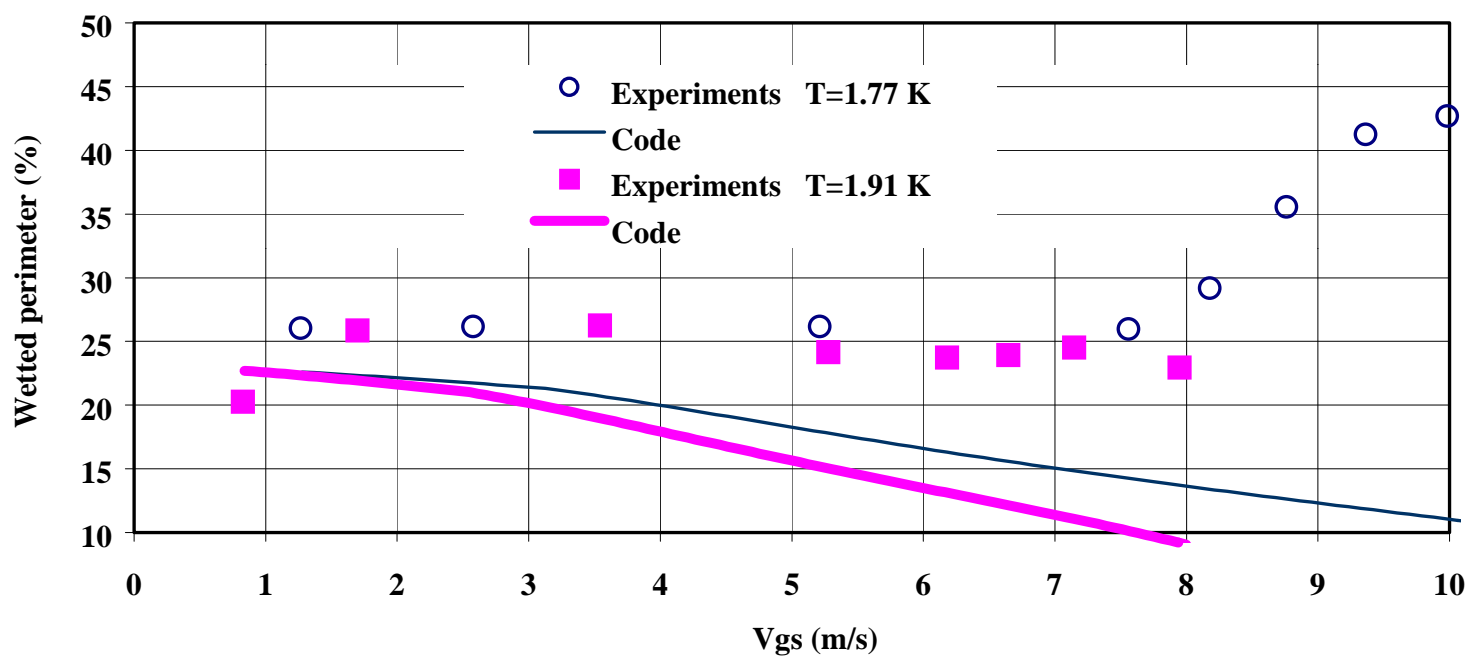

Figure 12. Temperature influence (slope $1.4 \%$, total mass flow $7.2 \mathrm{~g} / \mathrm{s}$, heat flux $22 \mathrm{~W} / \mathrm{m}^{2}$ ) 


\section{CONCLUSION}

We have investigated the thermohydraulic behaviour of He II two-phase flow. The large amount of data acquired in this experiments (only the most representative are presented here) confirms the excellent pressure loss prediction given by the Hanratty model.

Concerning heat transfer, apparent excess wetting appearing at high Vgs might possibly be due to an onset of change in flow pattern. Further measurements are needed to verify the presence of liquid droplets in the vapour flow. The code gives a conservative (under estimated) value for heat transfer.

\section{REFERENCES}

1. Lebrun P., "Superfluid Helium Cryogenics for the Large Hadron Collider Project at CERN" Cryogenics 34 (1994)

2. Rousset B., Gauthier A. \& Grimaud L., "Stratified Two-phase Superfluid Helium Flow: I" Cryogenics 37 (1997)

3. Grimaud L., Gauthier A., Rousset B. \& Delhaye J.M. "Stratified Two-phase Superfluid Helium FlowPart: II" Cryogenics 37 (1997)

4. Rousset B., Gauthier A. , Grimaud L. \& van Weelderen R., "Latest Developments on HeII co-current Two-phase Flow Studies" Advances in Cryogenics Engineering 43 (1998)

5. Taitel Y. \& Dukler A.E., "A Model for Predicting Flow Regime Transitions in Horizontal and Near Horizontal Gas-liquid Flow", AIChE Journal (1976), Vol. 22, 47-55.

6. Andritsos, N. \& Hanratty, T.J., "Influence of Interfacial Waves in Stratified Gaz-liquid Flows", AIChE Journal (1987), Vol. 33, 444-454. 